\title{
Cerium oxide nanoparticles improve liver regeneration after acetaminophen-induced liver injury and partial hepatectomy in rats
}

Bernat Córdoba-Jover ${ }^{1 \dagger}$, Altamira Arce-Cerezo ${ }^{1 \dagger}$, Jordi Ribera ${ }^{1}$, Montse Pauta ${ }^{1}$, Denise Oró ${ }^{1}$, Gregori Casals ${ }^{1,2}$, Guillermo Fernández-Varo ${ }^{1}$, Eudald Casals ${ }^{3,4,6}$, Victor Puntes ${ }^{3,4,5}$, Wladimiro Jiménez ${ }^{1,7}$ and Manuel Morales-Ruiz ${ }^{1,2,7^{*}}$ (D)

\begin{abstract}
Background and aims: Cerium oxide nanoparticles are effective scavengers of reactive oxygen species and have been proposed as a treatment for oxidative stress-related diseases. Consequently, we aimed to investigate the effect of these nanoparticles on hepatic regeneration after liver injury by partial hepatectomy and acetaminophen overdose.

Methods: All the in vitro experiments were performed in HepG2 cells. For the acetaminophen and partial hepatectomy experimental models, male Wistar rats were divided into three groups: (1) nanoparticles group, which received $0.1 \mathrm{mg} / \mathrm{kg}$ cerium nanoparticles i.v. twice a week for 2 weeks before $1 \mathrm{~g} / \mathrm{kg}$ acetaminophen treatment, (2) N-acetylcysteine group, which received $300 \mathrm{mg} / \mathrm{kg}$ of $\mathrm{N}$-acetyl-cysteine i.p. $1 \mathrm{~h}$ after APAP treatment and (3) partial hepatectomy group, which received the same nanoparticles treatment before partial hepatectomy. Each group was matched with vehicle-controlled rats.

Results: In the partial hepatectomy model, rats treated with cerium oxide nanoparticles showed a significant increase in liver regeneration, compared with control rats. In the acetaminophen experimental model, nanoparticles and $\mathrm{N}$-acetyl-cysteine treatments decreased early liver damage in hepatic tissue. However, only the effect of cerium oxide nanoparticles was associated with a significant increment in hepatocellular proliferation. This treatment also reduced stress markers and increased cell cycle progression in hepatocytes and the activation of the transcription factor NF-KB in vitro and in vivo.
\end{abstract}

Conclusions: Our results demonstrate that the nanomaterial cerium oxide, besides their known antioxidant capacities, can enhance hepatocellular proliferation in experimental models of liver regeneration and drug-induced hepatotoxicity.

Keywords: Liver regeneration, Oxidative stress, Cerium oxide nanoparticles, Partial hepatectomy, Acetaminopheninduced liver injury

\footnotetext{
*Correspondence: morales@clinic.cat

†Bernat Córdoba-Jover and Altamira Arce-Cerezo contributed equally to

this study

1 Biochemistry and Molecular Genetics Department, Hospital Clínic

of Barcelona, IDIBAPS, CIBERehd, 170 Villarroel St., 08036 Barcelona, Spain

Full list of author information is available at the end of the article
} 


\section{Background}

The liver regenerative capability is essential in the success of some treatments for chronic liver diseases, such as tumor resection and donor liver transplantation, which are conditioned by adequate liver regeneration $[1,2]$. However, there are some clinical situations in which the liver shows poor regenerative capacity, such as in the case of liver cirrhosis and severe drug-induced liver injury (DILI) $[3,4]$.

One pathological process that is common to these two clinical conditions is oxidative stress, which is caused by the excessive formation of reactive oxygen species (ROS). The presence of oxidative stress has been described in most of the clinical conditions associated with chronic liver injury (i.e.: nonalcoholic steatohepatitis, hepatitis $C$ viral infection, alcoholic liver cirrhosis) $[5,6]$. In addition, recent reports suggest that drug-induced oxidative stress also significantly correlate with increased DILI risk [7]. Concurrently, the association between high levels of oxidative stress and a reduction of antioxidant defenses has also been reported in most of these pathological situations $[8,9]$. According to the results obtained by several studies, the imbalance between the production of ROS and antioxidant defense in some of these liver diseases affects liver regeneration [10-12]. One of the reasons that explain this ROS effect is that ROS modulates the expression of a variety of regulators that play major roles in liver regeneration, including growth factors, transcription factors and cell cycle proteins such as $\beta$-catenin [13], cyclin D [14], p53 [15], Nrf2 [16] and JNK/p38 mitogen activated kinases [17].

Cerium oxide nanoparticles $\left(\mathrm{CeO}_{2} \mathrm{NPs}\right)$ have drawn considerable attention as a potential therapeutic tool in the prevention and treatment of oxidative stress related diseases. This interest relies on the multi-enzyme mimetic properties of $\mathrm{CeO}_{2} \mathrm{NPs}$ due to their unique electronic structure [18-20]. At the nanoscale, the oxygen vacancies that appear in the $\mathrm{CeO}_{2}$ nanocrystals modify their electronic structure enabling them to participate as a catalyst in a wide range of reactions (e.g. promoting the simultaneous oxidation of Carbon Monoxide (CO) and hydrocarbons to $\mathrm{CO}_{2}$ and the reduction of Nitrogen Oxides (NOx) to $\mathrm{N} 2$ in three way catalytic converters) [21]. Similarly, in biological contexts, it has been reported that cerium oxide nanoparticles can mimic enzymatic antioxidants such as superoxide dismutase [22] and catalase [23]. The beneficial effects of $\mathrm{CeO}_{2} \mathrm{NPs}$ have been reported in different clinical conditions associated with excess production of ROS such as neurology [24-27], diabetes [28, 29], chronic inflammation [30], cirrhosis [31] and cancer [32-34].

Considering the above, we hypothesize that $\mathrm{CeO}_{2} \mathrm{NPs}$ may improve liver regeneration by scavenging ROS in regenerative livers. To test our hypothesis we studied the hepatic regenerative process using two different rat experimental models of liver regeneration that are commonly associated with ROS production: partial hepatectomy (PHx) $[35,36]$ and DILI caused by acetaminophen (APAP) overdose. In the last case, the therapeutic effect of $\mathrm{CeO}_{2} \mathrm{NPs}$ was compared with the gold standard treatment for APAP-induced injury, $N$-acetylcysteine (NAC) [4].

\section{Results \\ Characterization and biodistribution of cerium oxide nanoparticles in rats}

Cerium oxide nanoparticles $\left(\mathrm{CeO}_{2} \mathrm{NPs}\right)$ were analyzed by HR-TEM. The engineered nanoparticles showed spherical morphology (Fig. 1a, b) and were predominantly in the size range of $4 \mathrm{~nm}$. The UV-visible absorption spectrum of $\mathrm{CeO}_{2} \mathrm{NPs}$ showed a characteristic absorption peak of $\mathrm{Ce}^{4+}$ at $298 \mathrm{~nm}$ (Fig. 1c). The X-ray diffraction pattern of the $\mathrm{CeO}_{2} \mathrm{NPs}$ showed pure $\mathrm{CeO}_{2} \mathrm{NPs}$ with the typical peak broadening characteristic of nanosize particles (Fig. 1d). Measured zeta potentials of the $\mathrm{CeO}_{2} \mathrm{NPs}$ were (+) $41.2 \mathrm{mV}$ (Fig. 1e). The hydrodynamic diameter of the $\mathrm{CeO}_{2} \mathrm{NPs}$ dispersed in saline solution at $\mathrm{pH}=5.5$ was $37 \mathrm{~nm}$ (Fig. 1f). These optimally engineered nanoceria were used further in our animal studies.

Several studies have described that after systemic distribution small inorganic NPs accumulate in the liver and spleen $[31,37]$. In agreement, $\mathrm{CeO}_{2} \mathrm{NPs}$ treated rats showed $\mathrm{CeO}_{2} \mathrm{NPs}$ retention into the liver and, to a lesser extent, in spleen as early as 90 min following i.v. injection. In these organs and at this time point, $\mathrm{CeO}_{2} \mathrm{NPs}$ reached concentrations of $160.9 \mu \mathrm{g}$ and $36.0 \mu \mathrm{g}$ of $\mathrm{CeO}_{2} \mathrm{NPs}$ per gram of tissue, respectively (Fig. 1g). Interestingly, cerium was still detected in liver and spleen for over 8 weeks although in lower concentrations. $\mathrm{CeO}_{2} \mathrm{NPs}$ retention was barely detected in the lungs and the kidneys of the rats at different time points after the intravenous injection (Fig. 1g).

To investigate the antioxidant properties of $\mathrm{CeO}_{2} \mathrm{NPs}$, we induced oxidative stress in the hepatocyte cell line HepG2 by $\mathrm{H}_{2} \mathrm{O}_{2}$ treatment, as previously reported $[38,39]$. ROS were assessed in these cells by using the dichlorofluorescein (DCF) assay [31]. When exposed to $\mathrm{H}_{2} \mathrm{O}_{2}, \mathrm{CeO}_{2} \mathrm{NPs}$-treated HepG2 cells showed a significant reduction in the accumulation of DCF in comparison to that observed in non-treated cells (Fig. 1h).

\section{Rats treated with $\mathrm{CeO}_{2} \mathrm{NPs}$ showed increased liver regeneration and hepatocellular proliferation after $\mathrm{PHx}$}

Oxidative stress mediate cell growth arrest and impairs hepatic regeneration in mice $[13,14]$. Therefore, testing new anti-oxidant drugs to improve liver regeneration 


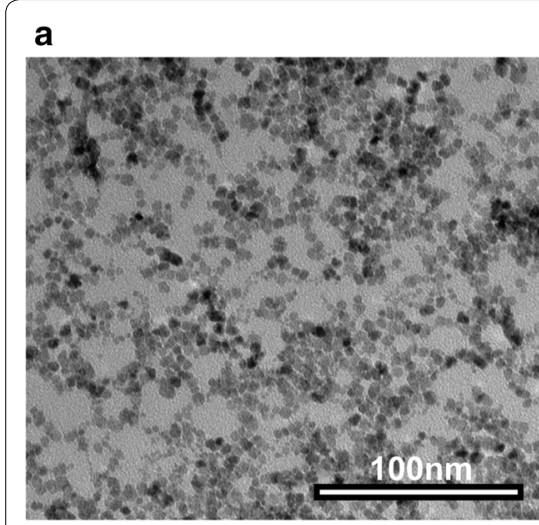

\section{b}
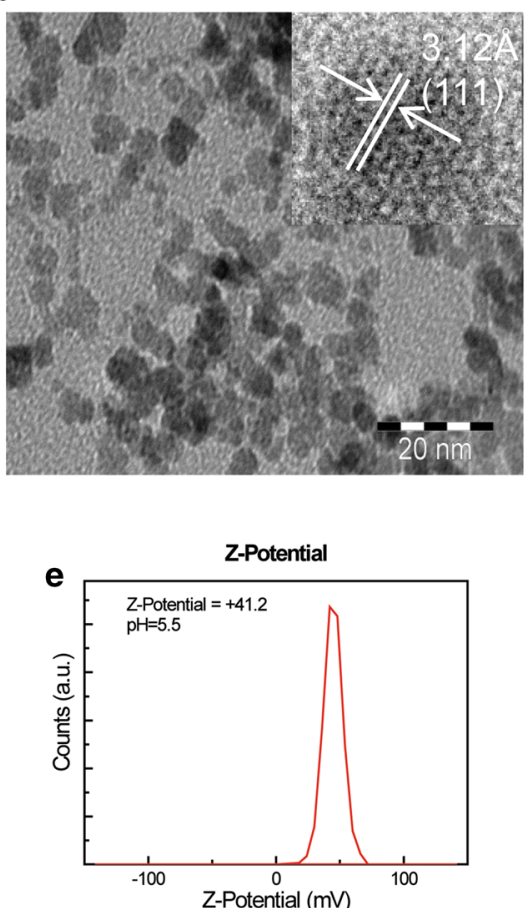

g
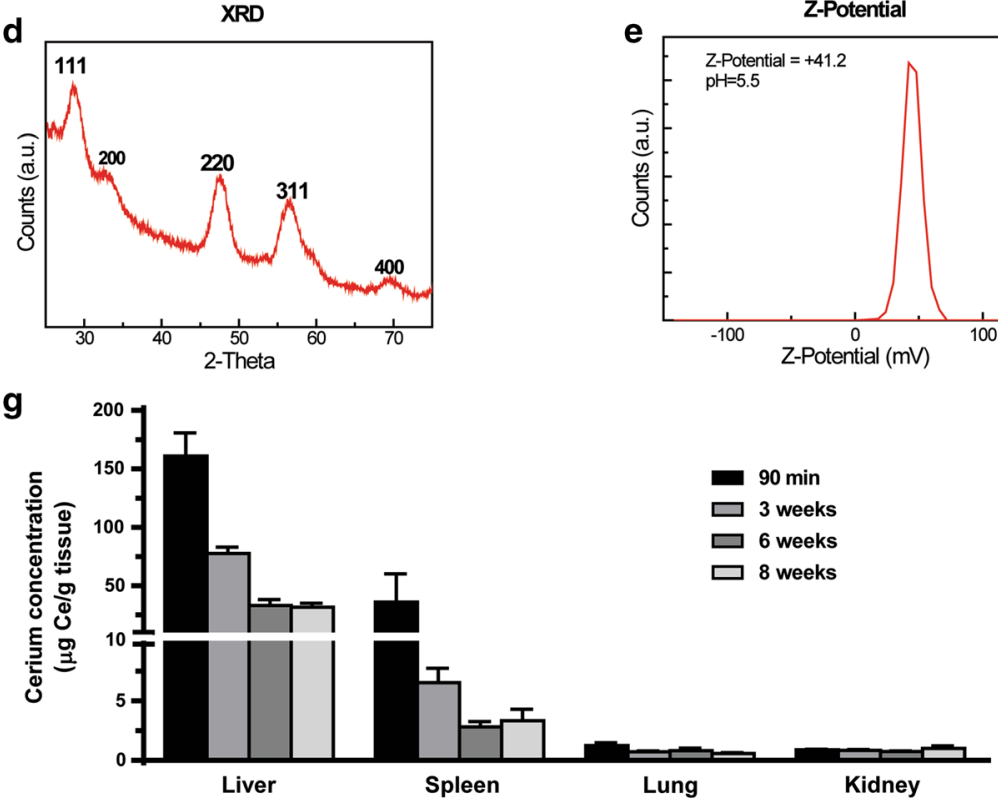

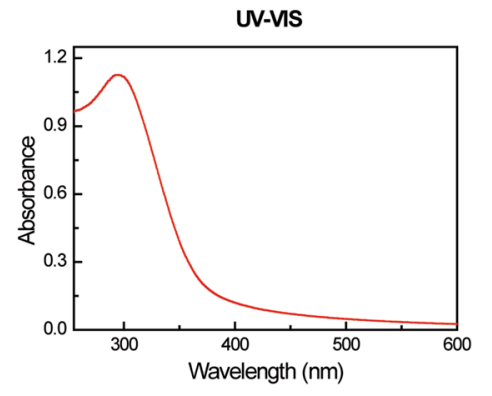

c

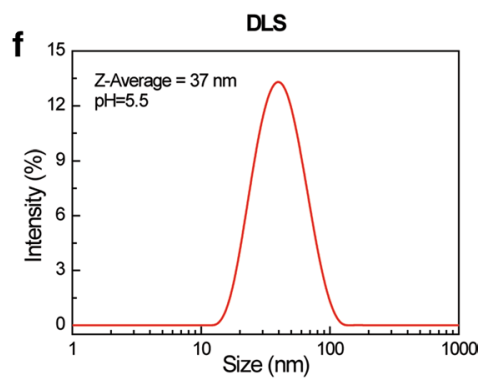

h

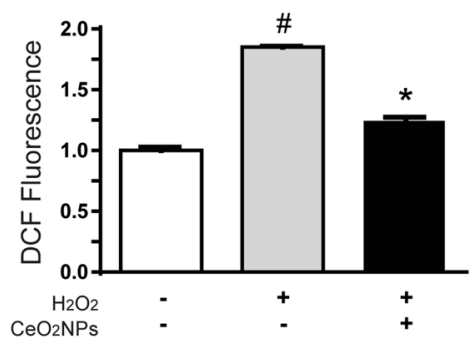

Fig. 1 Characterization of cerium oxide nanoparticles. a, b Representative TEM images of $\mathrm{CeO}_{2} \mathrm{NPs}$ at different magnifications showing the non-aggregate and spherical shape of the engineered nanoparticles. Inset in $\mathbf{b}$ is a High Resolution TEM image of single particle showing pure $\mathrm{CeO}_{2}$ atomic planes; $\mathbf{c}$ UV-Visible absorption spectrum of the as-synthesized $\mathrm{CeO}_{2} \mathrm{NPS}_{\mathbf{1}} \mathbf{d}$ XRD spectrum of the as-synthesized CeO $\mathrm{NPs}_{\text {after }}$ being

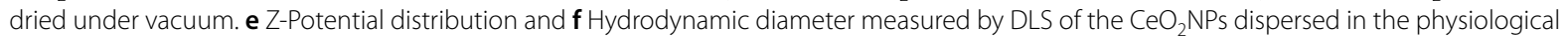
media (saline solution at $\mathrm{pH}=5.5) ; \mathbf{g}$ Cerium concentration in liver, spleen, lung and and kidney from rats treated with $\mathrm{CeO}_{2} \mathrm{NPs}_{\text {for }} 90$ min, 3,6 and 8 weeks ( $n=4$ for each group). $\mathbf{h}$ Oxidative stress was quantified in non-treated and $\mathrm{CeO}_{2} \mathrm{NPs}$-treated HepG2 cells by measuring DCF fluorescence in basal condition and after inducing oxidative stress with $2 \mathrm{mM} \mathrm{H}_{2} \mathrm{O}_{2}$ added to the culture medium $\left(^{\#} p<0.0001\right.$ vs basal and ${ }^{*} p<0.0001$ vs. non-treated, $n=10$ )

has clinical interest. To this aim, we studied the effect of $\mathrm{CeO}_{2} \mathrm{NPs}$ treatment on liver regeneration after performing PHx in rats. Rats were treated with $0.1 \mathrm{mg} / \mathrm{kg}$ $\mathrm{CeO}_{2} \mathrm{NPs}$ intravenously twice a week for 2 weeks before PHx. As shown in Fig. 2a, we did not observe any substantial change in body weight between the groups without treatment, vehicle treatment, and $\mathrm{CeO}_{2} \mathrm{NPs}$ treatment. Also, we performed liver laboratory tests in rat serum to quantify the liver function (glucose and albumin) and the liver damage (ALT and AST) in response to the $\mathrm{CeO}_{2} \mathrm{NPs}$ treatment in rats that were fasted for $12 \mathrm{~h}$. We did not detect any significant change of these laboratory parameters between vehicle and $\mathrm{CeO}_{2} \mathrm{NPs}$ treated groups (Additional file 1: Figure S1). These results support the concept that the $\mathrm{CeO}_{2} \mathrm{NPs}$ pretreatment is safe for the liver and is not associated with detectable side effects in the short term. Rats were sacrificed 6 days after the surgical procedure and the wet liver remnant weight/total body weight ratio was used to calculate the hepatic regenerative index. Rats treated with $\mathrm{CeO}_{2} \mathrm{NPs}$ showed a significant 

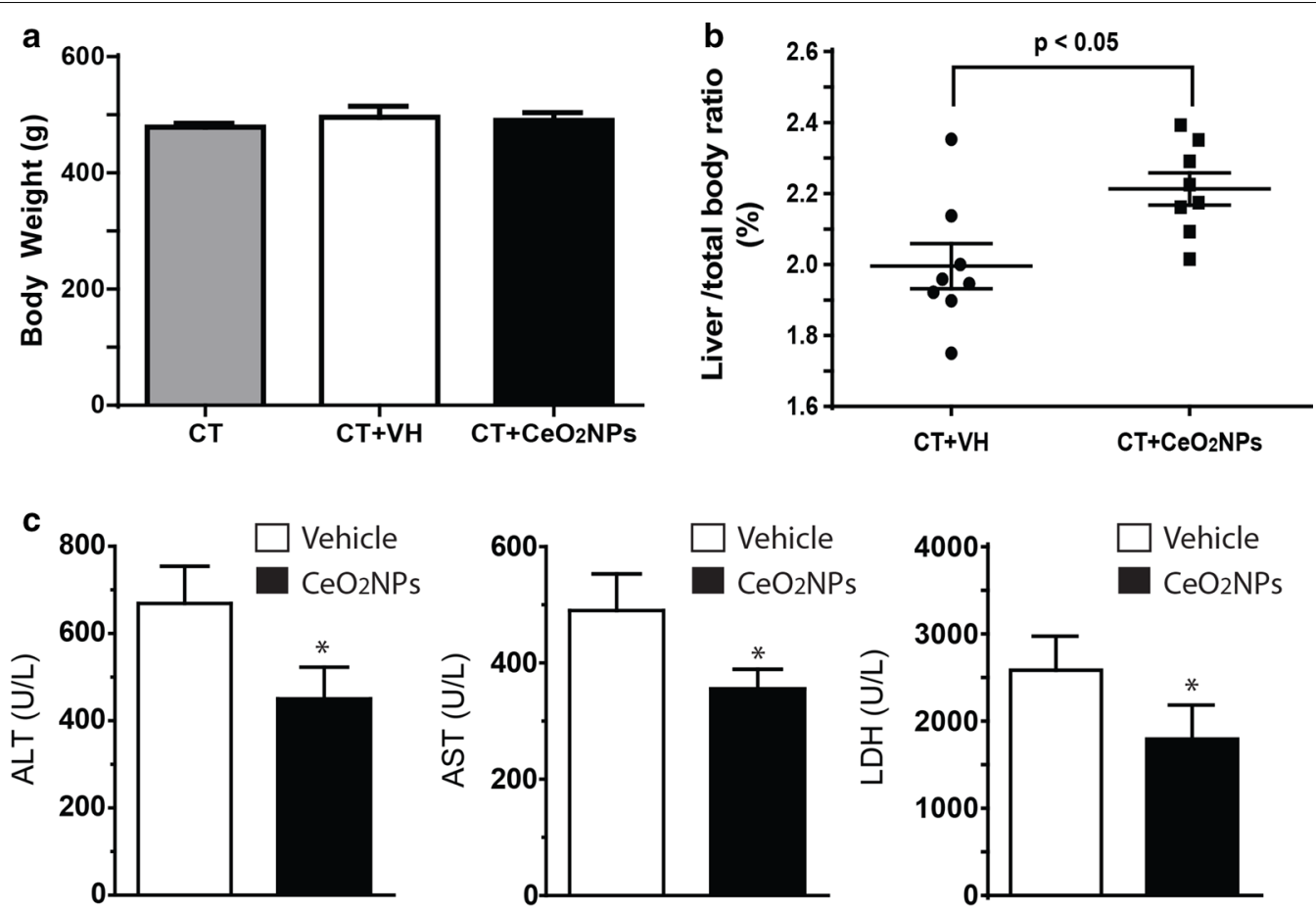

d

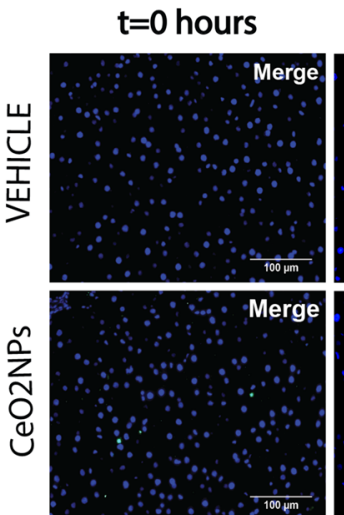

$t=24$ hours

$t=48$ hours

$\mathrm{t}=7$ days
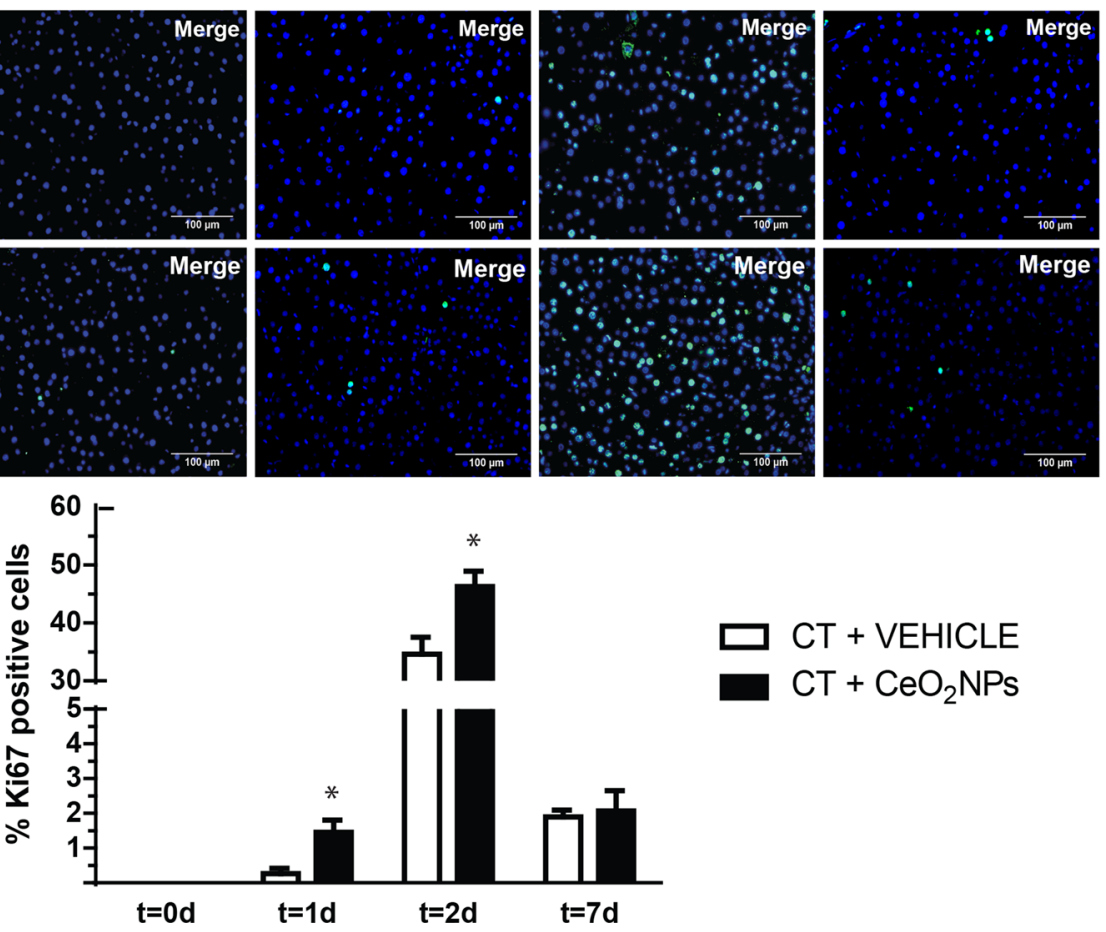

Fig. $2 \mathrm{CeO}_{2} \mathrm{NPs}$ treatment increased liver regeneration and cell proliferation after PHx. a Body weights of control rats without treatment and rats that received vehicle or $\mathrm{CeO}_{2} \mathrm{NPs}$ before $\mathrm{PHx}(\mathrm{n}=8)$. $\mathbf{b}$ Hepatic regenerative index at day 6 after $\mathrm{PHx}(\mathrm{n}=8, p<0.05)$. $\mathbf{c}$ Blood levels of ALT (* $\left.p<0.01\right)$, AST $\left({ }^{*} p<0.05\right)$ and LDH $\left({ }^{*} p<0.05\right)$ in vehicle or $\mathrm{CeO}_{2} \mathrm{NPs}$-treated rats after $3 \mathrm{~h}$ post-PHx $(\mathrm{n}=8 ;$ mean $\pm \mathrm{SEM})$. d Representative immunostaining for the Ki-67 antigen in liver histological sections of rats treated with either vehicle or $\mathrm{CeO}_{2} \mathrm{NPs}$ at different time points ( $\left.\mathrm{t}=0 \mathrm{~h}, 24 \mathrm{~h}, 48 \mathrm{~h}, 7 \mathrm{days}\right)$. Merged images show co-localization of Ki-67 (green) and nuclear DNA (DAPI, blue). Original magnification $\times 200$ ( $n=8$ for each group and treatment). On the bottom, percentage quantification of positive Ki-67 liver cells for each time point and treatment $(n=8 ; m e a n \pm S E M ; * p<0.05$ compared with vehicle at the same time points) 
$11 \%$ increase in the hepatic regenerative index, compared with vehicle-treated rats $(p<0.05)$ (Fig. 2b). The beneficial effect of $\mathrm{CeO}_{2} \mathrm{NPs}$ on liver regeneration was also accompanied by lower blood levels of alanine aminotransferase (ALT), aspartate aminotransferase (AST) and the enzyme lactate dehydrogenase (LDH) after $3 \mathrm{~h}$ post-PHx and compared with the vehicle group (Fig. 2c).

To further investigate the cause through which $\mathrm{CeO}_{2} \mathrm{NPs}$ improves liver regeneration, we assessed the expression of the cell proliferation marker Ki67 in liver sections of rats treated with nanoparticles. Rats receiving vehicle or $\mathrm{CeO}_{2} \mathrm{NPs}$ showed absence of hepatocellular proliferation in resting livers $(t=0 h)$ (Fig. 2d). However after $\mathrm{PHx}$, the remnant liver from rats treated with $\mathrm{CeO}_{2} \mathrm{NPs}$ showed a significant increase in $\mathrm{Ki} 67^{+}$-hepatocytes at day $1\left({ }^{*} p<0.05, t=24 \mathrm{~h}\right)$ that reached a maximum at $\mathrm{t}=48 \mathrm{~h}$ after partial hepatectomy, compared with vehicle $\left(44.6 \pm 4.5 \%\right.$ vs. $38.5 \pm 6.7 \% \mathrm{Ki} 67^{+}$ cells, " $p<0.05, t=48 \mathrm{~h}$ ); returning to nearly basal levels after 7 days (Fig. 2d). Therefore, improvement of liver regeneration caused by the $\mathrm{CeO}_{2} \mathrm{NPs}$ treatment is associated with enhanced hepatocyte proliferation.

\section{$\mathrm{CeO}_{2} \mathrm{NPs}$ treated rats showed decreased liver damage and increased hepatocellular proliferation after acetaminophen-induced liver injury}

The previous results show us the role played by $\mathrm{CeO}_{2} \mathrm{NPs}$ on liver regeneration in the context of basal levels of ROS. Next we assessed whether $\mathrm{CeO}_{2} \mathrm{NPs}$ is equally effective after ROS induction caused by APAP toxicity. In this experimental model, excessive oxidative stress plays a major role in APAP hepatotoxicity [40]. The injury induced after $48 \mathrm{~h}$ of APAP administration was assessed in three experimental groups: rats previously treated with $\mathrm{CeO}_{2} \mathrm{NPs}$, rats receiving vehicle and rats receiving a simultaneous treatment with NAC, which is the accepted clinical treatment for APAP overdose. Hematoxylin-eosin staining of livers from rats belonging to the vehicle experimental group showed that APAP administration induced severe liver injury characterized by massive necrosis, hepatocyte vacuolation and vascular congestion. Liver injury was significantly reduced in the $\mathrm{NAC}$ and the $\mathrm{CeO}_{2} \mathrm{NPs}$-treated groups, although vascular congestion was still present in both groups despite the $\mathrm{NAC}$ and the $\mathrm{CeO}_{2} \mathrm{NPs}$ treatments (Fig. 3a). As expected, APAP treatment induced a significant increase in hepatic ROS that was quantified by measuring 4-hydroxynonenal in the liver tissue (HNE), a widely accepted marker of lipid peroxydation and oxidative damage. Interestingly, both NAC (Fig. 3b second bar in the graph) and $\mathrm{CeO}_{2} \mathrm{NPs}$ (Fig. 3b third bar in the graph) are equally effective as antioxidant treatments for treating APAP-induced oxidative stress when compared with the vehicle condition
(Fig. 3b first bar in the graph). Despite sharing beneficial antioxidant properties, NAC and $\mathrm{CeO}_{2} \mathrm{NPs}$ treatments differed in their capability of stimulating hepatocellular proliferation. The liver from rats treated with $\mathrm{CeO}_{2} \mathrm{NPs}$ showed an extensive positivity for Ki67, compared with vehicle and NAC treated rats at day 2 after APAP injection $(40.08 \pm 5.04 \%, 10.70 \pm 1.69 \%$ and $13.53 \pm 3.13 \%$ Ki67 ${ }^{+}$cells, respectively; $\left.p<0.05\right)$ (Fig. 3c).

We performed additional experiments to characterize better the liver injury induced by APAP and the degree of recovery of the different experimental groups. To this end, we quantified the serum concentration of transaminases (ALT, AST), glucose and albumin from $\mathrm{CeO}_{2}$ NPs-treated and vehicle-treated rats at $\mathrm{t}=0 \mathrm{~h}$, $\mathrm{t}=48 \mathrm{~h}$, and $\mathrm{t}=96 \mathrm{~h}$. We found that the concentration of transaminases was significantly increased to a similar extent in the vehicle and the $\mathrm{CeO}_{2} \mathrm{NPs}$-treated groups 2 days after APAP administration $(\mathrm{t}=48 \mathrm{~h}$ compared with $\mathrm{t}=0 \mathrm{~h}$ ). However, $\mathrm{CeO}_{2} \mathrm{NPs}$ treatment was associated with a significant decline in serum ALT, reaching basal levels at $96 \mathrm{~h}$ after the APAP injection; compared with the vehicle group (Additional file 1: Figure S2). This recovery phase marker, which is a more specific marker of liver injury than AST, points to a more efficient recovery of the $\mathrm{CeO}_{2} \mathrm{NPs}$-treated liver after drug-induced liver damage.

\section{$\mathrm{CeO}_{2} \mathrm{NPs}$ treatment stimulates cell cycle progression in HepG2 cells and NFKB activation in vitro and in vivo}

To ensure the generalization of the finding that $\mathrm{CeO}_{2} \mathrm{NPs}$ improves hepatocyte proliferation in vivo after $\mathrm{PHx}$ and APAP-induced toxicity in rats, we characterized the dynamics of the cell cycle in the human hepatocyte cell line HepG2. As shown in Fig. $4 \mathrm{a}, \mathrm{CeO}_{2} \mathrm{NPs}$ treatment significantly decreased the percentage of HepG2 cells that underwent apoptosis following $48 \mathrm{~h}$ of serum starvation, as detected by propidium iodide staining and flow cytometry. Moreover, $\mathrm{CeO}_{2} \mathrm{NPs}$ treatment was associated with a higher percentage of HepG2 cells that were in the G2/M phase of the cell cycle, reflecting the stimulatory role played by $\mathrm{CeO}_{2} \mathrm{NPs}$ on cell cycle progression. We further validate these observations in the HepG2 cells by quantifying active caspase- 3 and cyclin D1 (markers of apoptosis and cell cycle progression, respectively). $\mathrm{CeO}_{2} \mathrm{NPs}$ treatment of HepG2 cells reduced the amount of activated caspase- 3 and increased the levels of cyclin D1 following $48 \mathrm{~h}$ of serum starvation (Fig. $4 \mathrm{~b}$ ).

The NF- $\kappa B /$ Rel family of transcription factors $(\mathrm{NF} \kappa \mathrm{B})$ is a central hub of signaling pathways that regulates apoptosis and cell proliferation. In addition, the activity $\mathrm{NF \kappa B}$ is modulated by ROS [41-43]. These confluent evidences let us to assess whether the activity of NF- $\mathrm{kB}$ is affected by the $\mathrm{CeO}_{2} \mathrm{NPs}$ treatment in vitro and in vivo. In HepG2 


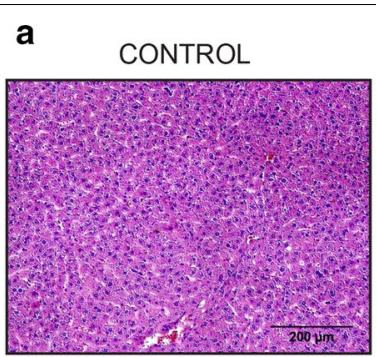

$\mathrm{CeO}_{2} \mathrm{NPS}+\mathrm{APAP}$

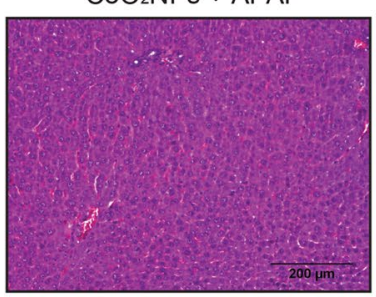

C

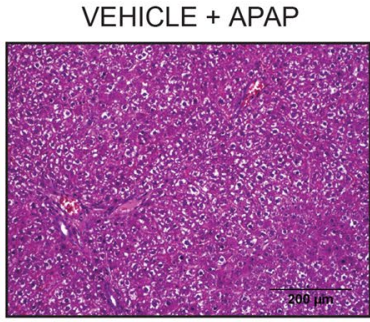

$\mathrm{NAC}+\mathrm{APAP}$
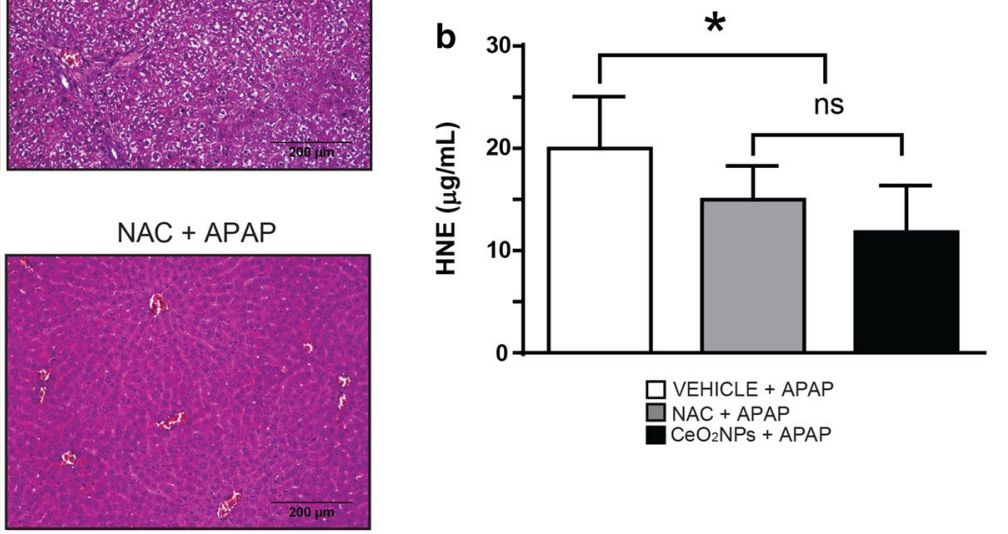

口VEICLE + APAP

DAC + APAP

$\mathrm{CEO}_{2} \mathrm{NPS}+\mathrm{APAP}$

VEHICLE + APAP

$N A C+A P A P$

$\mathrm{CeO} 2 \mathrm{NPs}+\mathrm{APAP}$
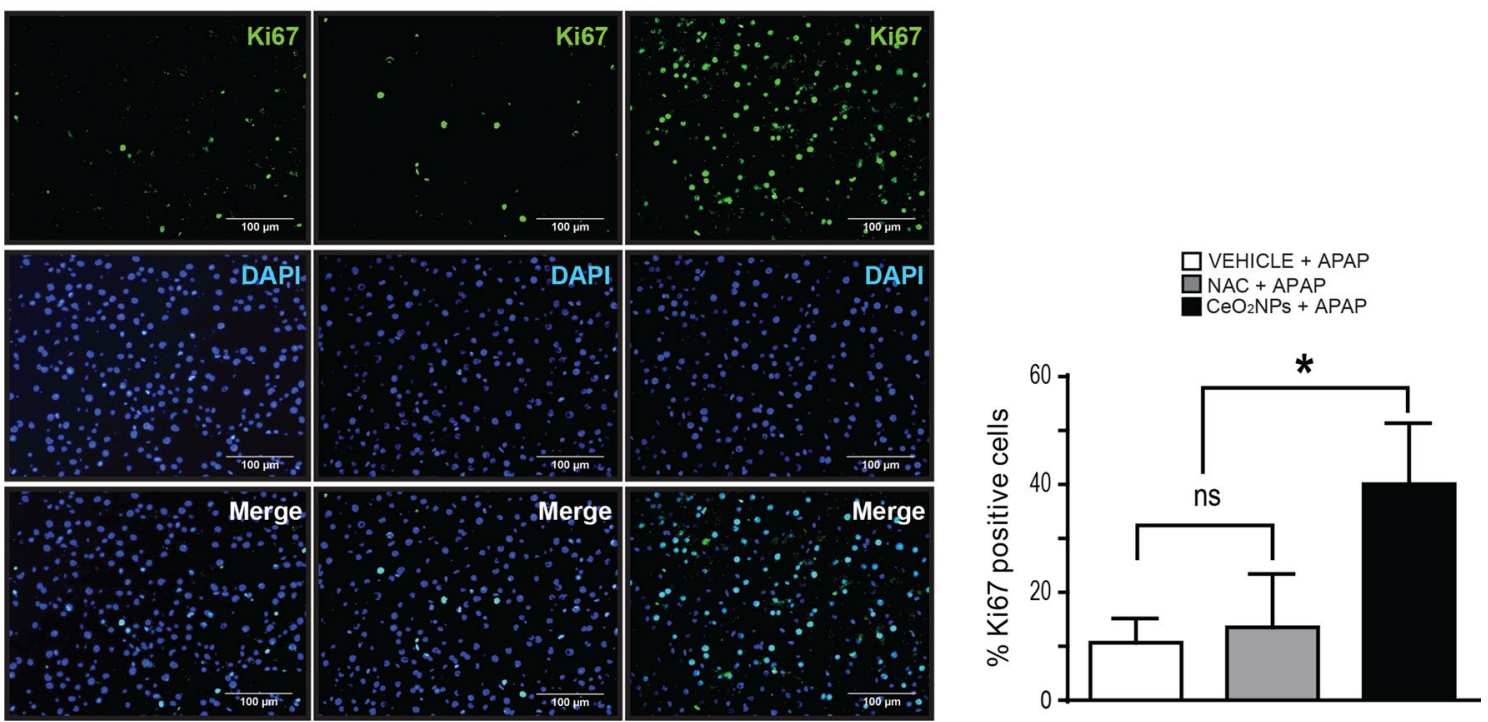

Fig. $3 \mathrm{CeO}_{2} \mathrm{NPs}$ treatment reduces histological damage and increases cell proliferation after APAP-induced injury. a Hematoxylin-eosin stained liver sections $(n=13)$. After vehicle or $\mathrm{CeO}_{2} \mathrm{NPs}$ treatments, rats received $1 \mathrm{~g} / \mathrm{kg}$ APAP and were sacrificed after $48 \mathrm{~h}$ (vehicle + APAP and $\mathrm{CeO}_{2} \mathrm{NPs}+\mathrm{APAP}$, respectively). Another group was treated with $300 \mathrm{mg} / \mathrm{kg} \mathrm{NAC} 1 \mathrm{~h}$ after APAP (NAC+ APAP). Also, healthy non-treated rats were included as experimental controls (upper left panel), $\times 100$. b Quantification of HNE in liver from vehicle + APAP, NAC + APAP and CeO ${ }_{2} N P s+$ APAP groups $\left(n=13\right.$; mean \pm SEM; $\left.{ }^{*} p<0.05\right)$. $\mathbf{c}$ Immunostaining for Ki-67 in liver of rats treated with vehicle + APAP, NAC + APAP and CeO 2 NPs + APAP. Ki-67 (green) and DAPI (blue), $\times 200$. On the right, quantification of Ki-67 positive cells $\left(n=13\right.$; mean \pm SEM; $\left.{ }^{*} p<0.05\right)$

(See figure on next page.)

Fig. $4 \mathrm{CeO}_{2} \mathrm{NPs}$ stimulates cell cycle progression and NF-KB activation. a Flow cytometry of HepG2 showing cell cycle profiles from propidium iodide DNA staining after vehicle or $\mathrm{CeO}_{2} \mathrm{NPs}$ treatment $\left(n=5 ;{ }^{*} p<0.01\right.$ and $\left.{ }^{*} p<0.05\right)$. b Western blot for activated caspase 3 and cyclin D1 abundance from HepG2 incubated with vehicle or $\mathrm{CeO}_{2} \mathrm{NPs}$. $\beta$-actin was used as loading control (mean $\pm \mathrm{SEM} ; \mathrm{n}=5 ;{ }^{*} p<0.05$ versus vehicle in the same experimental condition). O.D.: optical density. $\mathbf{c}$ Western blot for $\mathrm{K} \mathrm{KBa}$ abundance from HepG2 (mean $\pm \mathrm{SEM} ; \mathrm{n}=5$; ${ }^{*} p<0.05$ ). $\mathbf{d}$ Transcription factor immunosorbent assay for NF-KB (p65) activity in HepG2 $\left(n=5,{ }^{*} p<0.05\right)$. e Western blot for IKBa abundance in the liver vehicle and $\mathrm{CeO}_{2} \mathrm{NPs}$-treated rats before and $3 \mathrm{~h}$ post-PHx (mean $\left.\pm \mathrm{SEM} ; \mathrm{n}=5 ; \#<0.01\right)$ 


\section{Vehicle}

a

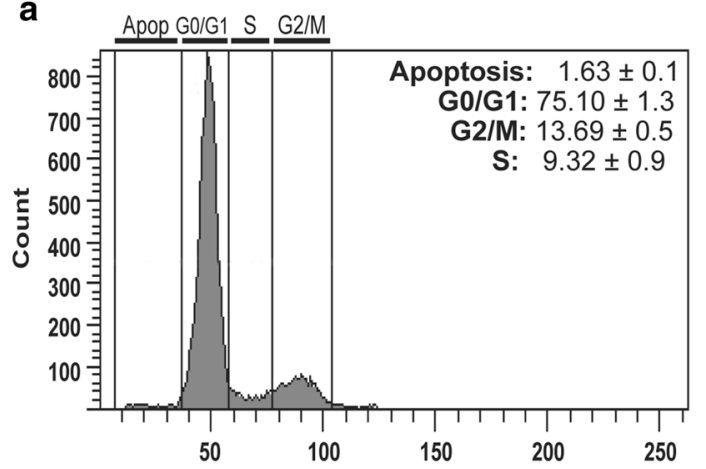

$\mathrm{CeO}_{2} \mathrm{NPs}$

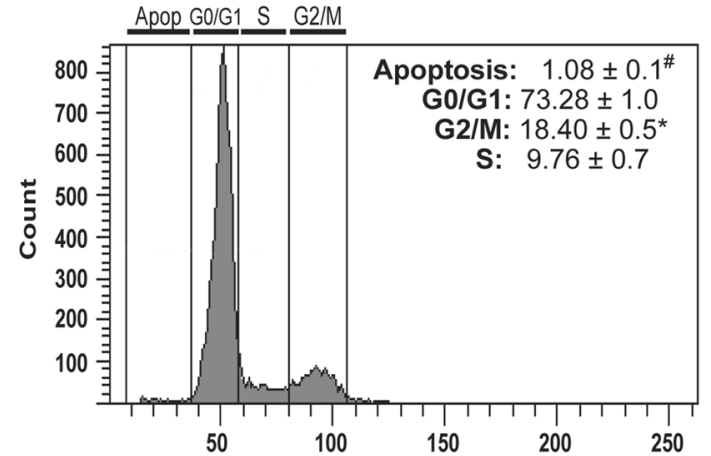

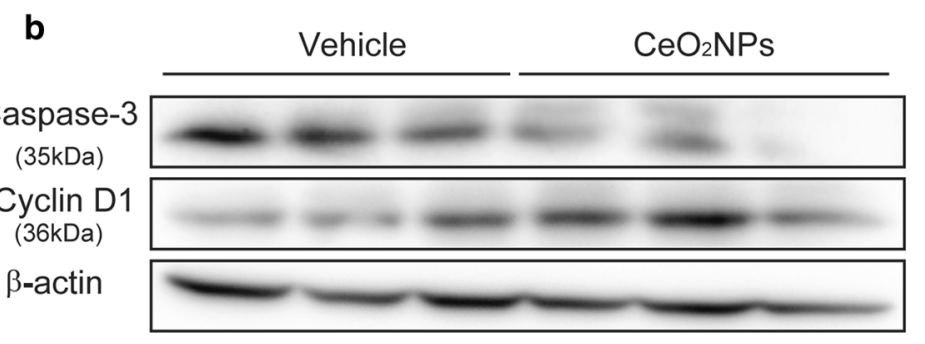
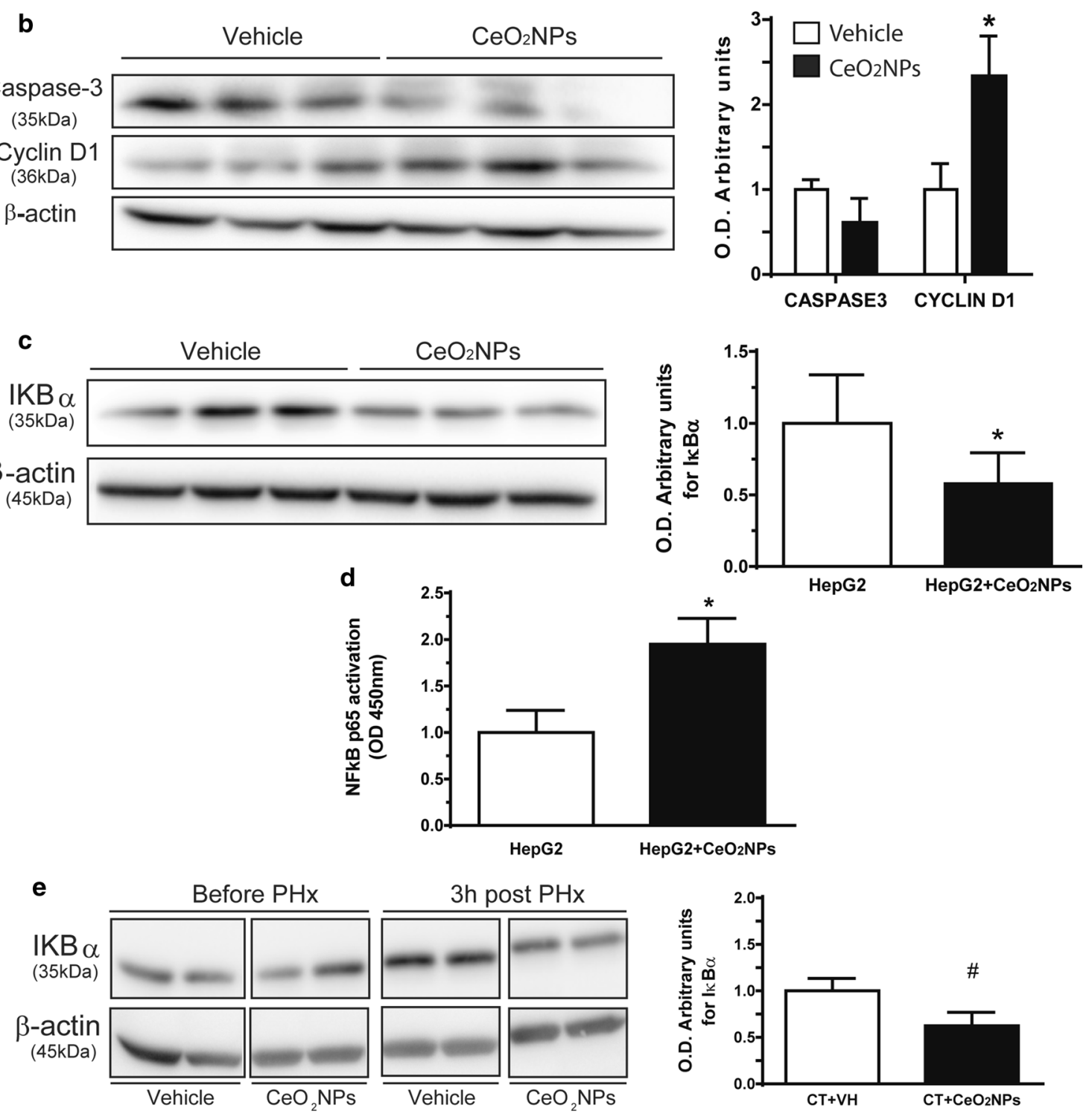
cells treated with $\mathrm{CeO}_{2} \mathrm{NPs}$, the abundance of ІкB $\alpha$ (that function as an inhibitor of $\mathrm{NF}_{\mathrm{K}} \mathrm{B}$ ) significantly decreased when compared to vehicle-treated HepG2 cells $(\mathrm{p}<0.05)$ (Fig. 4c). Next, the transcriptional activity of NF-kB was assessed by detecting specific p65 DNA binding in nuclear extracts from $\mathrm{CeO}_{2} \mathrm{NPs}$ treated and non-treated HepG2 cells. As shown in Fig. 4 d, $\mathrm{CeO}_{2} \mathrm{NPs}$ treated cells showed increased p65 transcriptional activity compared with non-treated HepG2 cells $(\mathrm{p}<0.05)$. We next investigated whether the described stimulation of NF- $\mathrm{KB}$ activity by $\mathrm{CeO}_{2} \mathrm{NPs}$ was also detected in regenerative livers in vivo. Before $\mathrm{PHx}$, there were no differences in the expression of $\mathrm{I}_{\kappa} \mathrm{B} \alpha$ in the livers from vehicle or $\mathrm{CeO}_{2} \mathrm{NPs}$ treated rats. However, and in agreement with the results obtained in HepG2, the abundance of IKB $\alpha$ was significantly lower in the livers from $\mathrm{CeO}_{2} \mathrm{NPs}$ treated rats $3 \mathrm{~h}$ after $\mathrm{PHx}$, compared with the group of rats receiving vehicle $(\mathrm{p}<0.01)$ (Fig. 4e).

\section{Discussion}

We previously described that $\mathrm{CeO}_{2} \mathrm{NPs}$ showed hepatoprotective activity in vivo against fibrosis [31]. Another study also demonstrated the beneficial effects of these nanoparticles against hepatic oxidative damage caused by the pyrrolizidine alkaloid monocrotaline, which causes oxidative vascular damage in the liver [44]. Considering this hepatoprotective role of $\mathrm{CeO}_{2} \mathrm{NPs}$, we further investigated whether these nanoparticles might also stimulate other hepatoprotective functions, such as liver regeneration. In the present study we describe for the first time that $\mathrm{CeO}_{2} \mathrm{NPs}$ stimulate liver regeneration in the rat experimental models of partial hepatectomy and DILI caused by acetaminophen overdose. Consistently with this observation, we demonstrated that $\mathrm{CeO}_{2} \mathrm{NPs}$ treatment decreases liver damage after PHx and APAPinduced liver injury. The treatment with $\mathrm{CeO}_{2} \mathrm{NPs}$ also leads to the reduction of oxidative stress markers and stimulates the cell cycle progression in hepatocytes and the activation of the transcription factor NF- $\mathrm{KB}$ in vitro and in vivo.

It is known that excess of oxidative stress inhibits efficient regeneration after partial hepatectomy or acute liver failure caused by DILI. For example, the genetic deficiency of Nrf2 (a regulator of the cellular antioxidant response) and UCP2 (an uncoupling protein of the electron transport chain) cause enhanced oxidative stress and impaired liver regeneration in partially hepatectomized mice [43]. Moreover, oxidative cellular damage in mitochondria and DNA is associated with deficient liver regeneration after acetaminophen toxicity [45]. Therefore, several strategies have been investigated by others to diminish ROS in the context of liver regeneration in preclinical models. For example, thymoquinone, an essential oil with free radical scavenging capacity, protects rat liver against ischemia/reperfusion injury [46] and prevents liver injury in hepatectomized mice under I/R by blunting oxidative stress, mitochondrial damage, endoplasmic reticulum stress and apoptosis [47]. Exogenous administration of GSH or resveratrol significantly decreased oxidative stress and protect against APAP-induced liver injury $[48,49]$. Similarly, pharmacological inhibition of JNK activity, which enhances mitochondrial-derived ROS production upon APAP toxicity, reduced liver damage [50]. Some drugs approved for its clinical use in different pathologies have also been tested pre-clinically for APAP hepatotoxicity. Both methylene blue and metformin reduced mitochondrial oxidant stress [51] and protected against APAP liver injury [52].

Our study has potential limitations regarding the APAP-induced toxicity model in rats. It has been shown that rats are more resistant to acetaminophen damage than mice [53]. Despite this observation, the presence of oxidative stress in the APAP-induced toxicity model in rats has broadly been demonstrated [54-56], regardless of the severity of the injury between species. Therefore, this experimental model in rats is still valid to test the antioxidant properties of $\mathrm{CeO}_{2} \mathrm{NPs}$ treatment on liver regeneration after drug-induced injury. Regarding the metabolism of APAP in the rat liver, we found in our study that the concentration of transaminases was significantly increased to a similar extent in the vehicle and the $\mathrm{CeO}_{2}$ NPs-treated groups 2 days after APAP administration. This result confirmed that there is significant toxicity induced by APAP overdose in our experimental rat model and that the $\mathrm{CeO}_{2} \mathrm{NPs}$ pretreatment does not modify the metabolism of APAP in the liver. Nevertheless, the quantification of an intermediary metabolite of APAP (i.e., $N$-acetyl-p-benzoquinone imine) would have supported more robustly this conclusion.

Our study presents an innovative treatment for diminish ROS in the context of liver regeneration using nanoparticles. Some of the advantages of using $\mathrm{CeO}_{2}$ nanomaterials over the traditional anti-oxidative drugs are: (1) minimal toxicity in cumulative doses [57, 58], (2) the multi-enzyme mimetic activities of $\mathrm{CeO}_{2} \mathrm{NPs}$, which targets several sources of ROS generation and (3) the continuous regeneration of the $\mathrm{CeO}_{2} \mathrm{NPs}$ catalytic activity, which avoids the exhaustion of its anti-oxidative properties [58]. Among these theoretical benefits over traditional drugs, we also observed superior therapeutic performance compared with the gold standard treatment used for acetaminophen toxicity in patients, NAC. In our study, $\mathrm{CeO}_{2} \mathrm{NPs}$ treatment is equally effective reducing oxidative stress and tissue damage in rats receiving APAP overdose compared with NAC. However, while NAC did not affect hepatocyte proliferation in injured livers, 
$\mathrm{CeO}_{2} \mathrm{NPs}$ robustly increased cell proliferation in vivo and in vitro. In addition, we observed a significant decrease in the percentage of $\mathrm{CeO}_{2} \mathrm{NPs}$-treated HepG2 cells that underwent apoptosis following $48 \mathrm{~h}$ of serum starvation, suggesting that the anti-apoptotic effect associated to the nanoceria treatment may also contribute to enhance liver regeneration.

NF- $\mathrm{kB}$ plays a major role in liver homeostasis and liver regeneration. For instance, NF- $k B$ (p65) knockout mice show embryo lethality and display massive hepatocyte apoptosis [59]. In addition, the transduction of rat livers with different forms of $I \kappa B$, an inhibitor of NF- $k B$ activity, before $\mathrm{PHx}$ was associated with impaired liver regeneration [60]. Furthermore, the inactivation of NF- $\mathrm{KB}$ in Kupffer cells as well as in hepatocytes impaired the regenerative process after PHx [61]. Here, we demonstrated that the treatment with $\mathrm{CeO}_{2} \mathrm{NPs}$ lead to the activation of the transcription factor NF- $\mathrm{kB}$ in vitro and in vivo. Our results are not sufficient to establish a robust link between NF- $\mathrm{kB}$ activation and the beneficial effects of $\mathrm{CeO}_{2} \mathrm{NPs}$ treatment on liver regeneration yet. However, the agreement between our findings and the studies mentioned above make this relationship plausible.

It has been described that oxidative stress can inhibit the transcriptional activity of $\mathrm{NF \kappa B}$ through different mechanisms including direct interaction with NF- $\mathrm{kB}$, inactivation of IKK (an IKB repressor), and alternative inhibitory phosphorylation of IKB $\alpha$ [41]. Our in vitro and in vivo results showed that $\mathrm{CeO}_{2} \mathrm{NPs}$ are associated with a significant decrease in the intracellular I $\kappa \mathrm{B} \alpha$ content, which is translated in the activation of NF-kB. Therefore, our findings suggest that the anti-oxidant property of $\mathrm{CeO}_{2} \mathrm{NPs}$ is responsible for the increase in NF- $\mathrm{kB}$ activation. However, our results are in disagreement with other studies which have shown that $\mathrm{CeO}_{2} \mathrm{NPs}$ treatment inhibits NF- $\mathrm{kB}$ in vivo mostly in the pathological context of sepsis [62-64]. One of the reasons that may explain the seemingly contradictory findings is differences in the $\mathrm{CeO}_{2} \mathrm{NPs}$ stability used in these studies, what has been recently recognized as key in order to employ $\mathrm{CeO}_{2} \mathrm{NPs}$ for medicine [22]. In addition, these studies used higher in vivo doses of $\mathrm{CeO}_{2} \mathrm{NPs}$ compared with ours (from $0.5 \mathrm{mg} / \mathrm{kg}$ to $3.5 \mathrm{mg} / \mathrm{kg}$ b.w. compared with $0.1 \mathrm{mg} / \mathrm{kg}$ b.w.). Our previous dosage standardization experiments [31] indicate that at higher doses $\mathrm{CeO}_{2} \mathrm{NPs}$ shows a hormetic-like dose response characterized by an increasing dose inefficacy in ROS scavenging.

\section{Conclusions}

In summary, drug-induced hepatotoxicity and impaired liver regeneration are major concerns in medical practice as they are leading causes of acute liver failure and liver transplantation. Our results demonstrated that $\mathrm{CeO}_{2} \mathrm{NPs}$, besides their known antioxidant capacities, can enhance liver regeneration in experimental models that replicate these two clinical scenarios. Hence, $\mathrm{CeO}_{2} \mathrm{NPs}$ treatment may provide avenues to overcome deficient liver regeneration in patients.

\section{Methods}

\section{Synthesis and characterization of $\mathrm{CeO}_{2} \mathrm{NPs}$}

$\mathrm{CeO}_{2} \mathrm{NPs}$ were synthesized by the chemical precipitation of cerium (III) nitrate hexahydrated (Sigma-Aldrich, St. Louis, MO, USA) in aqueous solution, as reported elsewhere [19]. Controlling the $\mathrm{pH}$ of synthesis, smallsized nanoceria can be obtained. Here, we used $4 \mathrm{~nm}$ nanoparticles at a concentration of $1 \mathrm{mg} / \mathrm{mL}$. The surface charge of the NPs was characterized by the Z-potential in a Z-sizer (Malvern, Worcestershire, UK) while the crystal size was characterized by High Resolution Transmission Electron Microscopy (HR-TEM) in the Tecnai G2 F20 (FEI, Oregon, USA). Nanocrystalline morphology and composition was analyzed by HR-TEM (Tecnai $200 \mathrm{kV}$ ) and XRD (Xpert Pannalytical, MA, USA), and the light interaction by UV-VIS spectroscopy (Shimatzu, Kyoto, Japan). Size distribution was computer analyzed by ImageJ (National Institutes of Health, Bethesda, MD, USA). $\mathrm{CeO}_{2} \mathrm{NPs}$ were stabilized with Tetramethylammonium hydroxide (TMAOH), which was used as vehicle in all the experiments as a control condition, and kept at $4{ }^{\circ} \mathrm{C}$ until use. Prior to the animal studies, $15 \mu \mathrm{L}$ from the nanoparticles solution were dispersed on a copper grid coated with a formvar film. The samples were then let to dry for TEM observation and digital photomicrographs were taken (BioScan Gatan, CA, USA). Free $\mathrm{CeO}_{2} \mathrm{NPs}$ samples available for evaluation if requested.

\section{Animal experimentation and In vivo $\mathrm{CeO}_{2} \mathrm{NPs}$ treatment} This study was performed in male Wistar rats (CharlesRiver, Saint Aubin les Elseuf, France). Rats were fed with standard chow diet and housed on a $12 \mathrm{~h}$ light/12 h dark cycle. For each experiment of this study, treated rats were administered $0.1 \mathrm{mg} / \mathrm{kg} \mathrm{CeO}_{2} \mathrm{NPs}$ dispersed in saline solution as a bolus $(500 \mu \mathrm{L})$, given intravenously through the tail vain twice a week for 2 weeks. Control groups without treatment and treated with vehicle (TMAOH) were also included in the study. At the end of each experiment rats were euthanized by isoflurane anesthesia overdose.

\section{$\mathrm{CeO}_{2} \mathrm{NPs}$ tissue quantification}

For tissue quantification, at the end of the 2 weeks treatment, rats were euthanized at days $1,21,42$, and 56 (90 min, 3, 6 and 8 weeks respectively) and their livers, spleens, lungs and kidneys dissected and kept at $-80^{\circ} \mathrm{C}$ for further analysis. For $\mathrm{CeO}_{2} \mathrm{NPs}$ quantification, samples 
were diluted in an aqueous solution of $\mathrm{HNO}_{3} 2 \% \mathrm{w} / \mathrm{w}$ (Trace Metal Basis; Sigma-Aldrich, St. Louis, MO, USA) and analyzed for cerium concentration by inductively coupled plasma mass spectrometry (ICP-MS, Agilent 7500; Agilent Technologies, California, USA). The quantitative results were obtained by interpolation in a standard curve obtained from a commercial $1000 \mathrm{ppm} \mathrm{Ce}$ standard (Sigma-Aldrich, St. Louis, MO, USA).

\section{Reactive oxygen species quantification}

Reactive oxygen species were measured by fluorescence spectrophotometry using $2^{\prime}, 7^{\prime}$-DCF-DA as a probe. For these experiments, HepG2 cells alone or treated with $\mathrm{H}_{2} \mathrm{O}_{2}$ in the presence or absence of $\mathrm{CeO}_{2} \mathrm{NPs}$ were washed with phosphate-buffered saline (PBS) and incubated with $10 \mu \mathrm{M}$ DCF-DA (Thermo Fisher Scientific, Waltham, MA, USA) in Dulbecco's modified Eagle medium (DMEM) for $40 \mathrm{~min}$ at $37^{\circ} \mathrm{C}$ in the dark. The supernatant was collected to measure the extracellular production of ROS, and the intensity of fluorescence was immediately read in a fluorescence spectrophotometer (FLUOstar Optima; BMG Labtech, Ortenberg, Germany) at $485 \mathrm{~nm}$ for excitation and at $520 \mathrm{~nm}$ for emission.

\section{In vitro $\mathrm{CeO}_{2} \mathrm{NPs}$ treatment}

The human cell line HepG2 (a suitable in vitro model system for the study of polarized human hepatocytes) was obtained from the American Type Culture Collection (ATCC; Manassas, VA, USA). HepG2 cells were cultured and maintained in DMEM containing 10\% FBS, $100 \mathrm{U} /$ $\mathrm{mL}$ penicillin and $100 \mu \mathrm{g} / \mathrm{mL}$ streptomycin at $37^{\circ} \mathrm{C}$ in a humidified atmosphere containing $5 \% \mathrm{CO}_{2}$. Cells were serum-starved and treated with $0.1 \mathrm{mg} / \mathrm{mL} \mathrm{CeO}_{2} \mathrm{NPs}$, or vehicle as a control condition, for $48 \mathrm{~h}$.

\section{Measurement of NF-KB activation}

NF- $k B$ activity in HepG2 cells was measured using a NF-kB Transcription Factor Assay Kit (specific for p65), following the manufacturer's instructions (Cayman Chemical, Ann Arbor, MI, USA). To this end, nuclear extracts from HepG2 were incubated with double stranded DNA immobilized in a 96-well plate that contained the $\mathrm{kB}$ response motif site. The complex p65-DNA was detected by enzyme-linked immunosorbent assay using specific primary antibody directed against p65 and a secondary antibody conjugated to HRP. The results were quantified by measuring absorbance at $450 \mathrm{~nm}$ in a FLUOstar Optima (BMG Labtech, Ortenberg, Germany).

\section{Statistical analysis}

Quantitative data were analyzed using GraphPad Prism, version 6 (GraphPad Software, Inc., San Diego, CA,
USA) and public libraries from The Comprehensive $\mathrm{R}$ Archive Network (CRAN; http://CRAN.R-project.org) rooted in the open source statistical computing environment $\mathrm{R}$, version 3.4 (http://www.R-project.org/). The statistical analysis of the results was performed using unpaired Student's t-tests and ANOVA models (with Tukey's post hoc test) with normally distributed data. For other type of data, the Mann-Whitney U-test and the Kruskal-Wallis tests (with Dunn post hoc test) were used. Results are expressed as mean \pm sem and considered significant at a $\mathrm{p}$ value lower than 0.05 .

Additional Materials and Methods are shown in Additional file 1 . Free $\mathrm{CeO}_{2} \mathrm{NPs}$ samples available for evaluation if requested.

\section{Supplementary information}

Supplementary information accompanies this paper at https://doi. org/10.1186/s12951-019-0544-5.

Additional file 1. Additional materials and methods, additional figures and references.

\section{Abbreviations}

$\mathrm{CeO}_{2} \mathrm{NPS}$ : cerium oxide nanoparticles; PHx: partial hepatectomy; APAP: acetaminophen; NAC: N-acetyl-cysteine; DILI: drug-induced liver injury; ROS: reactive oxygen species; DMEM: Dulbecco's modified Eagle medium; PBS: phosphate-buffered saline; DCF: dichlorofluorescein; HNE: 4-hydroxynonenal; PI: propidium iodide; ALT: alanine aminotransferase; AST: aspartate aminotransferase; LDH: lactate dehydrogenase.

\section{Acknowledgements}

We thank Ministerio de Economía y Competitividad, Fundació La Marató de TV3 and CIBERehd (Instituto de Salud Carlos III) for the grants and financial support to this research.

\section{Authors' contributions}

BC-J: experiments, procedures and writing of article; AA-C: experiments, procedures and writing of article; JR: experiments and generation of experimental models; MP: generation of experimental models; DO: experiments, GC: measurement of biochemical parameters, GF-V: measurement of biochemical parameters, EC: synthesis of $\mathrm{CeO}_{2} \mathrm{NPs}$ and writing of article, VP: synthesis of $\mathrm{CeO}_{2} \mathrm{NPs}$ and writing of article, WJ: concept, design and writing of article; MM-R: concept, design, experiments and writing of article. All authors read and approved the final manuscript.

\section{Funding}

This research was supported by grant from the Ministerio de Ciencia, Innovación y Universidades (SAF2016-75358-R to MM-R), co-financed by FEDER, European Union, a way of making Europe; Grant from the Ministerio de Sanidad, Consumo y Bienestar Social (PI15/00777 to GC); Grant from Wuyi University Funding for Hight Talents Introduction (2018TP010 to EC); Grant from Department of Education of Guangdong Province (2017KSYS010 to EC) and Fundació La Marató de TV3 (Marató 120930 to WJ). CIBERehd is financed by Instituto de Salud Carlos III.

\section{Availability of data and materials}

All data generated or analyzed during this study is available from the corresponding author on reasonable request.

\section{Ethics approval and consent to participate}

All animals received human care and all procedures were approved by the Investigation and Ethics Committee of Animal Experimentation of the University of Barcelona. 


\section{Consent for publication}

Not applicable.

\section{Competing interests}

The authors declare that they have no competing interests.

\begin{abstract}
Author details
${ }^{1}$ Biochemistry and Molecular Genetics Department, Hospital Clínic of BarceIona, IDIBAPS, CIBERehd, 170 Villarroel St., 08036 Barcelona, Spain. ${ }^{2}$ Working Group for the Biochemical Assessment of Hepatic Disease-SEQC-ML, Barcelona, Spain. ${ }^{3}$ Vall d'Hebron Institut of Research (VHIR), Barcelona, Spain. ${ }^{4}$ Institut Català de Nanociència i Nanotecnologia (ICN2), CSIC and The Barcelona Institute of Science and Technology (BIST), Barcelona, Spain. ${ }^{5}$ Institució Catalana de Recerca i Estudis Avançats (ICREA), Barcelona, Spain. ${ }^{6}$ School of Biotechnology and Health Sciences, Wuyi University, Jiangmen 529020, China. ${ }^{7}$ Department of Biomedicine-Biochemistry Unit, School of Medicine, University of Barcelona, Barcelona, Spain.
\end{abstract}

Received: 25 March 2019 Accepted: 18 October 2019

Published online: 31 October 2019

\section{References}

1. Fausto N, Campbell JS, Riehle KJ. Liver regeneration. Hepatology. 2006;43:S45-53.

2. Michalopoulos GK, DeFrances MC. Liver regeneration. Science. 1997;276:60-6.

3. Cho Lam Wong T, Mau Lo C. Resection strategies for hepatocellular carcinoma preoperative evaluation of liver function clinical and biochemical tests. Semin Liver Dis. 2013;33:273-81.

4. Wendon J, Cordoba J, Dhawan A, et al. EASL Clinical Practical Guidelines on the management of acute (fulminant) liver failure. J Hepatol. 2017;66:1047-81.

5. Morales-Ruiz M, Rodríguez-Vita J, Ribera J, Jiménez W. Pathophysiology of portal hypertension. Panvascular medicine. Berlin: Springer; 2015. p. 3631-65.

6. Ezhilarasan D. Oxidative stress is bane in chronic liver diseases: clinical and experimental perspective. Arab J Gastroenterol. 2018;19:56-64.

7. Xu JJ, Henstock PV, Dunn MC, Smith AR, Chabot JR, De Graaf D. Cellular imaging predictions of clinical drug-induced liver injury. Toxicol Sci. 2008;105:97-105.

8. Li S, Tan H-Y, Wang N, et al. The role of oxidative stress and antioxidants in liver diseases. Int J Mol Sci. 2015;16:26087-124.

9. Kaffe ET, Rigopoulou EI, Koukoulis GK, Dalekos GN, Moulas AN. Oxidative stress and antioxidant status in patients with autoimmune liver diseases. Redox Rep. 2015;20:33-41.

10. Ben Mosbah I, Duval H, Mbatchi S-F, et al. Intermittent selective clamping improves rat liver regeneration by attenuating oxidative and endoplasmic reticulum stress. Cell Death Dis. 2014;5:e1107.

11. Dayoub R, Vogel A, Schuett J, et al. Nrf2 activates augmenter of liver regeneration (ALR) via antioxidant response element and links oxidative stress to liver regeneration. Mol Med. 2013;19:237-44.

12. di Bello G, Vendemiale G, Bellanti F. Redox cell signaling and hepatic progenitor cells. Eur J Cell Biol. 2018;97:546-56.

13. Sun $S, X i e F, X u X$, et al. Advanced oxidation protein products induce $S$-phase arrest of hepatocytes via the ROS-dependent, $\beta$-catenin-CDK2mediated pathway. Redox Biol. 2018;14:338-53.

14. Barnouin $\mathrm{K}$, Dubuisson $\mathrm{ML}$, Child ES, et al. $\mathrm{H}_{2} \mathrm{O}_{2}$ induces a transient multiphase cell cycle arrest in mouse fibroblasts through modulating cyclin D and p21Cip1 expression. J Biol Chem. 2002;277:13761-70.

15. Geng Y, Zhang C, Lei J, et al. Walsuronoid B induces mitochondrial and lysosomal dysfunction leading to apoptotic rather than autophagic cell death via ROS/p53 signaling pathways in liver cancer. Biochem Pharmacol. 2017;142:71-86.

16. Murakami S, Motohashi $\mathrm{H}$. Roles of $\mathrm{Nrf2}$ in cell proliferation and differentiation. Free Radic Biol Med. 2015;88:168-78.

17. Tormos AM, Taléns-Visconti R, Nebreda AR, Sastre J. p38 MAPK: a dual role in hepatocyte proliferation through reactive oxygen species. Free Radic Res. 2013:47:905-16.
18. Esch F, Fabris S, Zhou L, et al. Electron localization determines defect formation on ceria substrates. Science. 2005;309:752-5.

19. Cafun J-D, Kvashnina KO, Casals E, Puntes VF, Glatzel P. Absence of $\mathrm{Ce}^{3+}$ sites in chemically active colloidal ceria nanoparticles. ACS Nano. 2013;7:10726-32

20. Wang Z, Shen X, Gao X, Zhao Y. Simultaneous enzyme mimicking and chemical reduction mechanisms for nanoceria as a bio-antioxidant: a catalytic model bridging computations and experiments for nanozymes. Nanoscale. 2019:11:13289-99.

21. Montini T, Melchionna M, Monai M, Fornasiero P. Fundamentals and catalytic applications of $\mathrm{CeO}_{2}$-based materials. Chem Rev. 2016;116:5987-6041.

22. Heckert EG, Karakoti AS, Seal S, SelfWT. The role of cerium redox state in the SOD mimetic activity of nanoceria. Biomaterials. 2008;29:2705-9.

23. Pirmohamed T, Dowding JM, Singh S, et al. Nanoceria exhibit redox statedependent catalase mimetic activity. Chem Commun. 2010;46:2736-8.

24. D'Angelo B, Santucci S, Benedetti E, et al. Cerium oxide nanoparticles trigger neuronal survival in a human Alzheimer disease model by modulating BDNF pathway. Curr Nanosci. 2009;5:167-76.

25. Kim CK, Kim T, Choi I-Y, et al. Ceria nanoparticles that can protect against ischemic stroke. Angew Chemie Int Ed. 2012;51:11039-43.

26. Ranjbar A, Soleimani Asl S, Firozian F, et al. Role of cerium oxide nanoparticles in a paraquat-induced model of oxidative stress: emergence of neuroprotective results in the brain. J Mol Neurosci. 2018;66:420-7.

27. Kalashnikova I, Mazar J, Neal CJ, et al. Nanoparticle delivery of curcumin induces cellular hypoxia and ROS-mediated apoptosis via modulation of $\mathrm{BCl}-2 / \mathrm{Bax}$ in human neuroblastoma. Nanoscale. 2017:9:10375-87.

28. Pourkhalili N, Hosseini A, Nili-Ahmadabadi A, et al. Biochemical and cellular evidence of the benefit of a combination of cerium oxide nanoparticles and selenium to diabetic rats. World J Diabetes. 2011;2:204-10.

29. Khurana A, Tekula S, Godugu C. Nanoceria suppresses multiple low doses of streptozotocin-induced Type 1 diabetes by inhibition of Nrf2/NF-kB pathway and reduction of apoptosis. Nanomedicine. 2018:13:1905-22.

30. Niu J, Azfer A, Rogers LM, Wang X, Kolattukudy PE. Cardioprotective effects of cerium oxide nanoparticles in a transgenic murine model of cardiomyopathy. Cardiovasc Res. 2007;73:549-59.

31. Oró D, Yudina T, Fernández-Varo G, et al. Cerium oxide nanoparticles reduce steatosis, portal hypertension and display anti-inflammatory properties in rats with liver fibrosis. J Hepatol. 2016;64:691-8.

32. Alili L, Sack M, Karakoti AS, et al. Combined cytotoxic and anti-invasive properties of redox-active nanoparticles in tumor-stroma interactions. Biomaterials. 2011:32:2918-29.

33. Nourmohammadi $E$, Khoshdel-sarkarizi H, Nedaeinia R, et al. Evaluation of anticancer effects of cerium oxide nanoparticles on mouse fibrosarcoma cell line. J Cell Physiol. 2019;234:4987-96.

34. Li H, Liu C, Zeng Y-P, et al. Nanoceria-mediated drug delivery for targeted photodynamic therapy on drug-resistant breast cancer. ACS Appl Mater Interfaces. 2016;8:31510-23.

35. Alizai PH, Bertram L, Fragoulis A, et al. In vivo imaging of antioxidant response element activity during liver regeneration after partial hepatectomy. J Surg Res. 2016;206:525-35.

36. Guerrieri F, Vendemiale G, Grattagliano I, Cocco T, Pellecchia G, Altomare E. Mitochondrial oxidative alterations following partial hepatectomy. Free Radic Biol Med. 1999;26:34-41.

37. Comenge J, Sotelo C, Romero F, et al. Detoxifying antitumoral drugs via nanoconjugation: the case of gold nanoparticles and cisplatin. PLOS ONE. 2012; $7:$ e47562

38. Ling Liau L, Suzana M, Ghani Nur Azurah A, Hui Chua K. Hydrogen peroxide induces acute injury and up-regulates inflammatory gene expression in hepatocytes: an in vitro Model. Sains Malaysiana. 2016;45:451-8.

39. Jiang C, Yu S, Jiang Z, et al. N-acetyl-serotonin protects HepG2 cells from oxidative stress injury induced by hydrogen peroxide. Oxid Med Cell Longev. 2014. https://doi.org/10.1155/2014/310504.

40. Du K, Ramachandran A, Jaeschke H. Oxidative stress during acetaminophen hepatotoxicity: sources, pathophysiological role and therapeutic potential. Redox Biol. 2016;10:148-56.

41. Morgan MJ, Liu Z. Crosstalk of reactive oxygen species and NF-kB signaling. Cell Res. 2011;21:103-15.

42. Imran M, Lim IK. Regulation of Btg2/TIS21/PC3 expression via reactive oxygen species-protein kinase C-NFKB pathway under stress conditions. Cell Signal. 2013;25:2400-12. 
43. Horimoto M, Fülöp P, Derdák Z, Wands JR, Baffy G. Uncoupling protein-2 deficiency promotes oxidant stress and delays liver regeneration in mice. Hepatology. 2004;39:386-92.

44. Amin KA, Hassan MS, Awad E-ST, Hashem KS. The protective effects of cerium oxide nanoparticles against hepatic oxidative damage induced by monocrotaline. Int J Nanomedicine. 2011;6:143-9.

45. Viswanathan P, Sharma Y, Gupta P, Gupta S. Replicative stress and alterations in cell cycle checkpoint controls following acetaminophen hepatotoxicity restrict liver regeneration. Cell Prolif. 2018;51:e12445.

46. Bouhlel A, Ben Mosbah I, Hadj Abdallah N, et al. Thymoquinone prevents endoplasmic reticulum stress and mitochondria-induced apoptosis in a rat model of partial hepatic warm ischemia reperfusion. Biomed Pharmacother. 2017;94:964-73.

47. Bouhlel A, Bejaoui M, Ben Mosbah I, et al. Thymoquinone protects rat liver after partial hepatectomy under ischaemia/reperfusion through oxidative stress and endoplasmic reticulum stress prevention. Clin Exp Pharmacol Physiol. 2018. https://doi.org/10.1111/1440-1681.12961.

48. Saito C, Zwingmann C, Jaeschke $\mathrm{H}$. Novel mechanisms of protection against acetaminophen hepatotoxicity in mice by glutathione and N-acetylcysteine. Hepatology. 2010;51:246-54.

49. Du K, McGill MR, Xie Y, Bajt ML, Jaeschke H. Resveratrol prevents protein nitration and release of endonucleases from mitochondria during acetaminophen hepatotoxicity. Food Chem Toxicol. 2015;81:62-70.

50. Han D, Dara L, Win S, et al. Regulation of drug-induced liver injury by signal transduction pathways: critical role of mitochondria. Trends Pharmacol Sci. 2013;34:243-53.

51. Lee KK, Imaizumi N, Chamberland SR, Alder NN, Boelsterli UA. Targeting mitochondria with methylene blue protects mice against acetaminophen-induced liver injury. Hepatology. 2015;61:326-36.

52. Du K, Ramachandran A, Weemhoff JL, et al. Editor's highlight: metformin protects against acetaminophen hepatotoxicity by attenuation of mitochondrial oxidant stress and dysfunction. Toxicol Sci. 2016;154:214-26.

53. Davis D, Potter W, Jollow D, Mitchell J. Species differences in hepatic glutathione depletion, covalent binding and hepatic necrosis after acetaminophen. Life Sci. 1974;14:2099-109.

54. Lakshmi T, Sri Renukadevi B, Senthilkumar S, et al. Seed and bark extracts of Acacia catechu protects liver from acetaminophen induced hepatotoxicity by modulating oxidative stress, antioxidant enzymes and liver function enzymes in Wistar rat model. Biomed Pharmacother. 2018;108:838-44.
55. Al-Brakati AY, Fouda MS, Tharwat AM, Elmahallawy EK, Kassab RB, Abdel Moneim AE. The protective efficacy of soursop fruit extract against hepatic injury associated with acetaminophen exposure is mediated through antioxidant, anti-inflammatory, and anti-apoptotic activities. Environ Sci Pollut Res. 2019;26:13539-50.

56. Porto HKP, Grando MD, Ramalho LNZ, et al. Exposure to acetaminophen impairs vasodilation, increases oxidative stress and changes arterial morphology of rats. Arch Toxicol. 2019;93:1955-64.

57. Muhammad F, Wang A, Qi W, Zhang S, Zhu G. Intracellular antioxidants dissolve man-made antioxidant nanoparticles: using redox vulnerability of nanoceria to develop a responsive drug delivery system. ACS Appl Mater Interfaces. 2014;6:19424-33.

58. Xu C, Qu X. Cerium oxide nanoparticle: a remarkably versatile rare earth nanomaterial for biological applications. NPG Asia Mater. 2014;6:e90.

59. Beg AA, Sha WC, Bronson RT, Ghosh S, Baltimore D. Embryonic lethality and liver degeneration in mice lacking the RelA component of NF-kB. Nature. 1995;376:167-70.

60. limuro Y, Nishiura T, Hellerbrand C, et al. NFkappaB prevents apoptosis and liver dysfunction during liver regeneration. J Clin Investig. 1998;101:802-11.

61. Maeda S, Kamata H, Luo J-L, Leffert H, Karin M. IKK $\beta$ couples hepatocyte death to cytokine-driven compensatory proliferation that promotes chemical hepatocarcinogenesis. Cell. 2005;121:977-90.

62. Chen $G$, Xu Y. Biosynthesis of cerium oxide nanoparticles and their effect on lipopolysaccharide (LPS) induced sepsis mortality and associated hepatic dysfunction in male Sprague Dawley rats. Mater Sci Eng C. 2017:83:148-53.

63. Selvaraj $V$, Manne ND, Arvapalli R, et al. Effect of cerium oxide nanoparticles on sepsis induced mortality and NF-KB signaling in cultured macrophages. Nanomedicine. 2015;10:1275-88.

64. Selvaraj V, Nepal N, Rogers $S$, et al. Inhibition of MAP kinase/NF-kB mediated signaling and attenuation of lipopolysaccharide induced severe sepsis by cerium oxide nanoparticles. Biomaterials. 2015;59:160-71.

\section{Publisher's Note}

Springer Nature remains neutral with regard to jurisdictional claims in published maps and institutional affiliations.
Ready to submit your research? Choose BMC and benefit from:

- fast, convenient online submission

- thorough peer review by experienced researchers in your field

- rapid publication on acceptance

- support for research data, including large and complex data types

- gold Open Access which fosters wider collaboration and increased citations

- maximum visibility for your research: over 100M website views per year

At BMC, research is always in progress.

Learn more biomedcentral.com/submissions 